Lepr. Rev. (1970) 41, 126-128

\title{
Abstracts
}

The following abstract is reprinted, with permission, from Trop. Dis. Bull., 1970, 67, 1:

I. Thalidomide in the treatment of lepra reactions, by P. La Rosa and A. Casciano. Minerva Derm., 1968, 43, 166. English summary.

The authors from Messina treated 15 patients suffering from leprosy by thalidomide. Six patients had the lepromatous form, 7 the intermediate form, and 2 the tuberculoid form. The dose of thalidomide used was $300 \mathrm{mg} /$ day, 2 tablets of $50 \mathrm{mg}$ being given every 8 hours for a period which depended on the regression (or not) of the lepra reactions, but was usually from a few days to a week. No other drugs were given during the thalidomide treatment. When there was repression of the lepra reactions the dose was reduced progressively to $50 \mathrm{mg} /$ day and continued for up to 30 days, hut in the cases where there was no repression of the lepra reactions after 8 days, the thalidomide treatment was suspended.

The results were: lepromatous form, 6 patients treated, 3 excellent, I moderate, 2 failures; intermediate form, 7 patients treated, 3 excellent, 2 moderate, 2 failures; tuberculoid form, 2 patients treated, both showed moderate improvement. The effects of the drug were usually seen after 24 hours and became more evident in the days following. Side-effects noted were asthenia, loss of appetite, and somnolence but these lessened with the improvement in the clinical condition and ceased with the reduction in dosage. No changes caused by the drug were seen after the usual laboratory tests on blood, liver function or urine. The authors state that although only a few patients were treated and the results favourable in only about $50 \%$ the drug would appear at present to be the treatment of election in lepra reactions.

\section{K. I)unscombe.}

The following 4 abstracts are reprinted, with permission, from Trop. Dis. Bull., 1970, 67, 2:

2. Immunologic reactivity in patients with leprosy, by .J. N. Sheagren, J. B. Block, J. $\mathrm{R}$. Trautmanand $\mathrm{S}$. M. Wolfe. Ann. Intern. Med. 1969, 70, 295.

Alterations in some aspects of immunologic reactivity in a group of (38) patients with leprosy were found primarily in patients with the lepromatous form of the disease (32). Such patients had impaired lymphocyte transformation to streptolysin $\mathrm{O}$ antigen. The ability to form circulating antibodies was preserved. Levels of IgG and $\operatorname{IgA}$ immunoglobulins were increased in lepromatous disease while IgM levels were normal in all groups. The concentration of serum complement was normal in all patients with uncomplicating disease but was elevated in those lepromatous patients suffering erythema nodosum leprosum (ENL) reactions or amyloidnsis. Reticuloendothelial system phagocytic function was increased in patients with lepromatous leprosy and especially in those with ENI, reactions.

3. Secondary amyloidosis in leprosy, by .J. C. SAChdex, D. PURI and S. Bansal. Lepr. Indin, $1969,41,73$.

Three cases of amyloidosis secondary to lepromatous leprosy have been reported. Two patients developed nephrotic syndrome and the third renal failure due to amyloid deposits in kidney. The definite diagnosis of renal amyloidosis was established by positive renal biopsy. Although amyloidosis has been regarded as rare in lepromatous patients in India, yet we should be on the look-out for this complication. The efforts may prove rewarding in an occasional patient.

4. Hyperreflexia and spastic paralysis among New Caledonian leprosy patients, by .J. A. Brody, Y. Yase, G. Chemier and Y. Philippe. Am. .J. Trop. Med. Hyg., 1969, 18, 132.

The authors confirm the findings of Desmoulins and Zeldine (Trop. D)is. Bull., 1969, 66, abstract 213), who reported spastic paralysis of upper neurone type confined to patients with leprosy in New Caledonia who had beer treated with sulphones. Complete neurological investigations of patients with leprosy with suggestive symptoms revealed 18 suffering from frank spasticity, mainly of the lower limbs. Further enquiry among the remaining in-patients with leprosy disclosed that 10 out of 41 Melanesians examined (out of a trital of 99), and 5 out of 10 Europeans examined (out of 48) had pathologically hyperactive reflexes in the upper extremities. (It is noteworthy that the prevalence rates of leprosy are said to be approximately equal in the Melanesian and the European population.) No case of spasticity was discovered among 23 patients with tuberculosis, and none has been reported from the largest hospital complex in New Caledonia.

The authors compared this syndrome with cases of spasticity reported among malnourished populations and war prisoners, and consider that it appears to be more closely related to nutritional and toxic syndromes than to motor-neurone disease reported from other Pacific areas (or to a condition induced by a virus with a very long silent period). It has not been recorded from countries where treatment of leprosy with sulphones has been widespread for years. 
(Perhaps a key sentence in this paper is the following: "The major industry on the island is nickel-mining; almost the entire population is engaged in some work related to this industry." It is not impossible that dapsone may potentiate or accelerate the known neurotoxic properties of nickel.)

$$
\text { S. G. Browne. }
$$

5. Histoid leprosy, by R. E. MAxsfield . Arch. Path., $1969,87, .580$.

This is an account of 5 new cases of histoid leprosy. Points of interest are that all of the patients had a history of leprosy of at least 20 years duration, and that 4 of the 5 had become resistant to the drug with which they were being treated; bacilli were abundant and the lesions were rapidly growing.

The pathology of histoid lesions has already been fully described by Wade (Trop. Dis. Bull., 1964, 61, $673)$. The object of the present communication is to draw the attention of general pathologists to the differential diagnosis of histoid leprosy and of dermatofibroma and similar skin tumours, which may also be found in patients with leprosy.

$$
\text { I). S. Ridley. }
$$

The following 4 abstracts are reprinted, with permission, from Trop. Dis. Bull., 1970, 67, 3:

6. Pharmacodynamic effects of the diformyl derivative of diaminodiphenyl sulfone (DDS), by D. M. Aviado, G. Marroquin and S. R. Shore. Int. J. Lepr., 1968, 36, 432.

The antimalarial activity of the diformyl derivative (DFD) of dapsone (DDS) is presumably not due to conversion of the drug in vivo to the parent substance, because it is more active, and the experiments reported in this paper were aimed at confirming that the drug is not changed in vivo and at characterizing its pharmacological action.

The intravenous LD50 of DFD in the anaesthetized cat was $255-350 \mathrm{mg} / \mathrm{kg}$ which compares with 55-180 $\mathrm{mg} / \mathrm{kg}$ for DDS. In the anaesthetized dog, infused intramuscularly at the rate of $1 \mathrm{mg} / \mathrm{kg} /$ minute, it caused hypotension and increased pulmonary resistance.

The blood levels after oral administration of DFD and DDS to rabbits gave similar blood levels and as urinary excretion studies did not reveal any evidence of DFD being excreted more slowly than DDS, the high antimalarial activity of DFD reported earlier (Trop. I)is. Bull., 1968, 65, abstract 493) cannot be explained by differences in rates of excretion. In immature rats, $10 \mathrm{mg}$ DDS per $\mathrm{kg}$ caused $19 \%$ goitrogenic effect, as measured by increase in thyroids, whereas $100 \mathrm{mg}$ DFD per kg had no similar effect. In rabbits there was no evidence of abnormal forms of haemoglobin being produced.
The authors suggest that, if DFD can be shown to have activity in mouse infectiors with Mycobacterium leprae, it should be tried in human irfections.

S. R. M. Bushby.

7. Ghemotherapeutic trials in leprosy. 6. Pilot study of the riminophenazine derivative B 663 in low dosage (100 $\mathrm{mg}$ twice weekly) in the treatment of lepromatous leprosy, by M. F. R. Waters. Int. J. Lepr., 1968, 36, 391.

Clofazimine (B 663, Geigy) was given at a dose of $100 \mathrm{mg}$ twice weekly to 8 light-skinned patients with lepromatous leprosy, previously untreated. The Morphological Index fell from an average of 30 to $0.5 \%$ in $4 \frac{1}{2}$ months, and the clinical and histological improvement was similar to that of patients taking clofazimine at a dose of $300 \mathrm{mg}$ daily, or dapsone in standard doses. Skin pigmentation developed more slowly and was less istense than in the case of patients taking higher doses of clofazimine, and no diarrhoea occurred.

The author discusses the difficulties of blind assessment of patier:ts taking a drug that produces changes in skin colour.

(For Part 5, see Trop. Dis. Bull., 1968, 65, abstract 925$.

S. G. Browne.

8. Isolation of a strain of Mycobacterium lepraemurium from normal laboratory mice, by S. R. Pattyn and G. Verdolaege-van Loo. Ann. Soc. Belg. Méd. Trop., 1969, 49, 465.

'Isolation of a strain of Mycobacterium lepraemurium from 'normal' laboratory white mice is related.

Its implication on foot pad passage work with Myco. leprae is discussed."

9. Biochemical and ultrastructural study of the relationship between lysosomal enzyme activities and chemotherapy, by F. KANETSUNA and T. IMAEDA. Int. J. Lepr., 1968, 36, 417.

This paper describes the morphological and biochemical effects of dapsone (DDS), glucosulphone (Promin) and streptomycin on lysosomal activities in mice infected with Mycobacterium lepraemurium. Studies by other workers have shown that chemotherapy with dapsone elicits the formation of the opaque droplets around leprosy bacilli in the human disease, and because these droplets contain acid phosphatase they were named lysosomal substance. As this substance is not seen around bacilli in murine leprosy, the authors conside: that these lesions could be useful for confirming whether or not chemotherapy provokes the formation of opaque droplets in human lepra cells. 


\section{Abstracts}

In 2 experiments, mice were infected with Myco. lepraemurium; in the first, some of the animals were treated with sodium glucosulphone, and in the second, groups were treated with sodium glucosulphone, dapsone or streptomycin. In both experiments, uninfected mice were also treated with the drugs. At the end of periods of treatment of 3 and 6 weeks, the livers, srleens and mesenteric lepromas were removed from the mice of the first experiment and the lepromas and serum were removed after 6 and 19 weeks' treatment from the mice of the second experiment. The $\beta$-glucuronidase, acid phosphatase and cathepsin contents of the organs were estimated, and lysosomes and the lepromas were examined by the ultrastructuralcytochemical techniques of Ericsson and Trump (Lab. Invest., 1964, 13, 1427).

The results indicate that the enzymes are enhanced in the organs of the infected mice, irrespective of whether or not the organs contain bacilli; the serum levels were also raised, suggesting that the enzymes are released from the tissues. There was no evidence that the hydrolases accumulated in the lysosomes as opaque droplets, although there was evidence of major amounts dispersed throughout the cytoplasm. Streptomycin provoked increases of hydrolase activity without increasing the opaque droplets in lepra cells or bacteriafree histiocytes. Dapsone, on the other hand, not only increased the hydrolase activity in the lesions, but also enhanced the formation of the acid-phosphatase active droplets; sodium glucosulphone had less effect.

On the basis of these findings, the authors consider that anti-leprosy drugs, especially dapsone and streptomycin, not only have anti-mycobacterial activity, but also elicit lysosomal hydrolase activities that may indirectly inhibit bacterial metabolism.

S. R. M. Bushby. 